\title{
ESTUDO DA EFICIÊNCIA DOS SOLVENTES NA EXTRAÇÃO DO ÓLEO DA AMÊNDOA DA TERMINALIA CATAPPA LINN
}

\author{
L. D. SILVA NETO ${ }^{1}$, E. N. SILVA ${ }^{1}$, C.M.B. PEREIRA ${ }^{2}$, J. I. SOLETTI ${ }^{1}$ e S.H.V. CARVALHO ${ }^{1}$. \\ ${ }^{1}$ Universidade Federal de Alagoas, Departamento de Engenharia Química \\ ${ }^{2}$ Universidade Federal de Alagoas, Departamento de Ciências Agrárias \\ E-mail para contato: 1d_neto@hotmail.com
}

\begin{abstract}
RESUMO - A Terminalia Catappa Linn é uma espécie exótica, rustica e perene adaptada a regiões tropicais e subtropicais, particularmente localizadas em áreas costeiras. Como consequência da migração humana, essa árvore foi introduzida e naturalizada em muitos países tropicais do mundo, incluindo o Brasil. O processo de extração de óleos vegetais tem evoluído constantemente com objetivo de aumentar a eficiência, reduzir o consumo de energia e causar menor impacto ambiental. O aumento na eficiência desta tecnologia ficou restrito à maximização da remoção do óleo, à redução na perda de solvente para o meio ambiente e minimização dos custos operacionais. O processo de extração por solvente foi realizado em duplicata pelo método Soxhlet padrão, com os solventes hexano, metano e etanol, onde resultados mostraram que a eficiência do solvente hexano, sobre a semente in natura, atingiu o percentual mais alto, de aproximadamente $60 \%$ de óleo extraído, o que indica que processo de extação por solvente, para a amêndoa da Terminalia catappa l, foi satisfatório.
\end{abstract}

\section{INTRODUÇÃO}

A utilização da biomassa não é um processo recente, no entanto sua produção de forma eficiente e sustentável vem se desenvolvendo ao longo dos anos (Kojiro,2010). Isso é reflexo da crescente demanda por fontes alternativas de energias que vem aumentando o interesse em pesquisas para encontrar novas matérias primas mais eficiente. Tem-se desenvolvido e aperfeiçoado tecnologias de conversão da biomassa mais eficientes, a fim de melhorar o processo e reduzir impactos socioambientais.

O óleo de origem vegetal é uma fonte de energia renovável sendo um dos principais produtos extraídos das plantas. Cerca de $80 \%$ é usado para aplicações na indústria de alimentos, os outros $20 \%$ são destinados para a fabricação de detergentes, cosméticos, lubrificantes, tintas, vernizes e plásticos (Silva, 2009; Reda, et al., 2007). O processo de extração de óleos vegetais tem evoluído constantemente com objetivo de aumentar a eficiência, reduzir o consumo de energia e causar menor impacto ambiental. O aumento na eficiência desta tecnologia ficou restrito à maximização da remoção do óleo, à redução na perda de solvente para o meio ambiente e minimização dos custos operacionais. Esses processos variam de acordo com a matéria-prima processada. Os métodos mais empregados na extração de óleos vegetais são extração por solvente, a prensagem ou ainda uma combinação de ambos. O processo de extração por solvente ocorre quando o solvente é 
aquecido, e através do seu ponto de ebulição é conduzido ao topo do tubo extrator, onde será condensado entrando em contato com a amostra contida nesse tubo, o que promoverá a difusão do solvente para o interior da celular e consequentemente a dissolução do óleo no solvente (Andrade, 2014).

\subsection{Caracterização da Amendoeira (Terminalia Catappa Linn)}

A Terminalia Catappa Linn é uma árvore exótica, que cresce em regiões tropicais e subtropicais, localizadas em áreas costeiras. Esta arvore foi introduzida em muitos países tropicais do mundo, a exemplo do Brasil, devido à migração humana. E se naturalizaram nas praias da costa brasileira, devido a sua fácil germinação e pela sombra que suas folhas proporcionam (Francis, et al.,1989). De acordo com Collins et al., (1992), é uma árvore nativa da Índia, com altura variando entre 25 e $45 \mathrm{~m}$. Mas, nos trabalhos publicados por THOMSON E EVANS (2006), essa altura máxima é de 20 metros. Esses atores que divergem na altura da arvore, descrevem característica físicas semelhante para a espécie. As árvores florescem e frutificam anualmente, mas em muitas áreas como no Havaí, Fiji e Tonga, frutificam e florescem continuamente ao longo do ano.

Apesar da amêndoa ser considerada comestível (Thomson e Evans, 2006), é pouco utilizado na alimentação humana, o que se explica pela dificuldade de ser extraída do fruto, a qualidade comestível variável e a ausência de variedades com sementes maiores (De Paula, 2008). Já de acordo com relatos de Teixeira, (2010), as amêndoas são consumidas em zonas rurais do Taiwan, sul da Nigéria, Malásia e Índia. Esse fruto é constituído por uma parte externa (exocarpo), pela polpa (mesocarpo) e em seu interior por um caroço duro (endocarpo), contendo a semente (amêndoa) (Vareschi, 1979 citado por González et al., 2005). (Figura 1).

Figura 1 - Partes do fruto maduro e seco, da Terminalia catappa. 1. Amêndoa; 2. Endocarpo (parte lenhosa); 3. Mesocarpo (parte fibrosa); 4. Epicarpo.
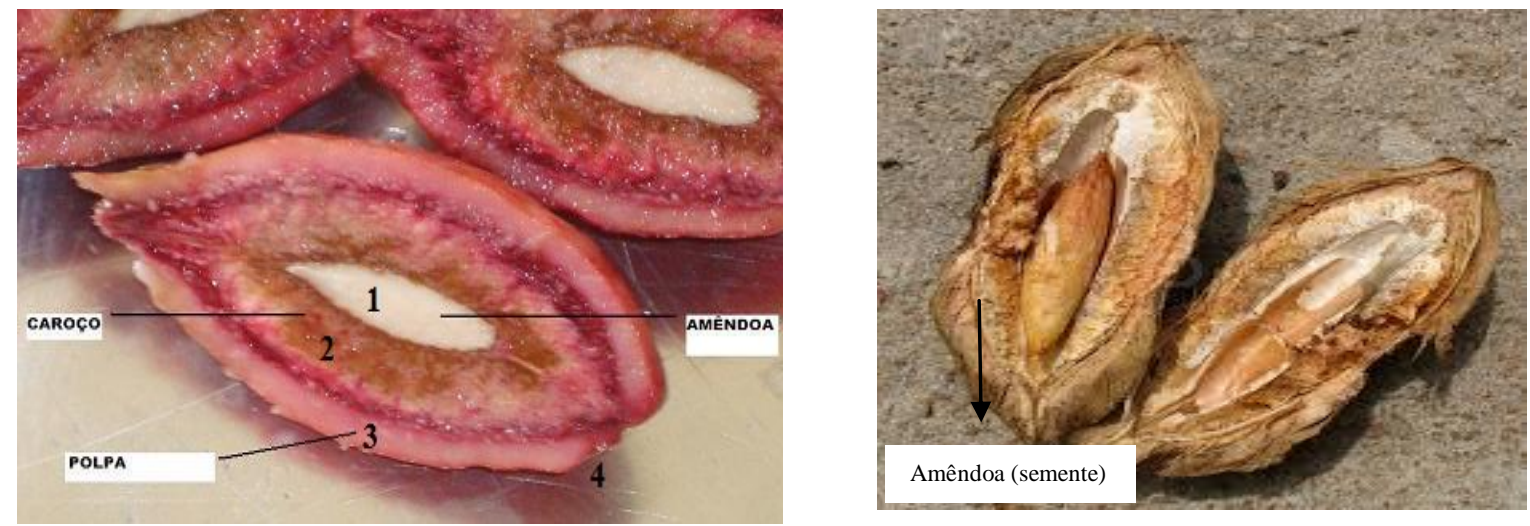

Fonte: Texeira, 2010

\section{METODOLOGIA}

As amostras de amêndoas foram coletadas de árvores distintas, período de novembro de 2015 a março de 2016 na cidade de Maceió. Uma parte foi de amendoeira do Campus da Universidade, e o restante foi coletado nas intermediações da cidade. 
Foram coletados aproximadamente $10 \mathrm{~kg}$ do fruto, selecionados do seu estádio final de maturação ao seco, da amendoeira. Estes foram postos para secagem, ao ar livre, durante 15 dias. Esse período permitiu que a amêndoa se desprendesse da casca rígida que a envolve, o que facilitou sua retirada. Para isso, foi utilizada uma ferramenta de corte, a qual foi adaptada para esse fim. Conforme mostra a Figura 2 (A1). Ao termino obtivesse um total aproximado de $3 \mathrm{~kg}$ de amêndoas seca. Figura 2 (A2).

\section{Figura 2- A1 Ferramenta de corte para retirada da amêndoa, A2 amêndoa retirada do fruto.}
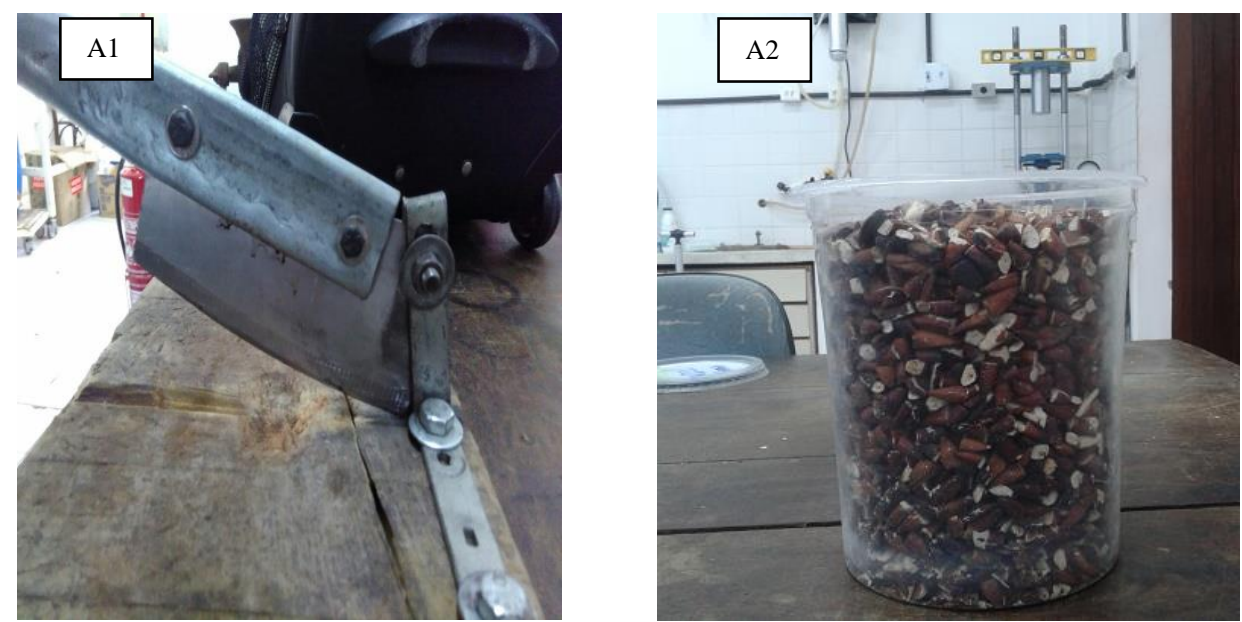

Fonte: Autor (2016)

Após a retirada das amêndoas, estas foram desidratadas em estufa por 24 horas a uma temperatura em torno de $60^{\circ} \mathrm{C}$, pois temperaturas superiores a $60^{\circ} \mathrm{C}$ acarretaria na queima das sementes. Esse processo de secagem da amêndoa antes da extração é para reduzir o máximo possível o teor de água contido na amêndoa.

\subsection{Extração por solvente}

Para a extração por solvente, foram utilizadas aproximadamente $3 \mathrm{~g}$ das amêndoas in natura trituradas. $\mathrm{O}$ processo foi realizado em duplicata pelo método Soxhlet padrão, com os solventes: hexano, metano e etanol, no tempo de 12h, no extrator Soxhlet B-811 (Figura 3). $\mathrm{O}$ experimento avaliou os tipos de solvente. Cada amostra foi envolvida em um sache de papel filtro e introduzida no extrator. O reservatório do equipamento foi preenchido com 250 $\mathrm{ml}$ do solvente determinado. $\mathrm{O}$ extrator foi programado de acordo com o método para cada um dos solventes, este descrito no próprio extrator. As misturas óleo-solvente foram conduzidas para o processo de separação no próprio extrator. O rendimento de óleo foi estimado através da diferença entre a massa da amostra inicial e a massa de amostra final. 


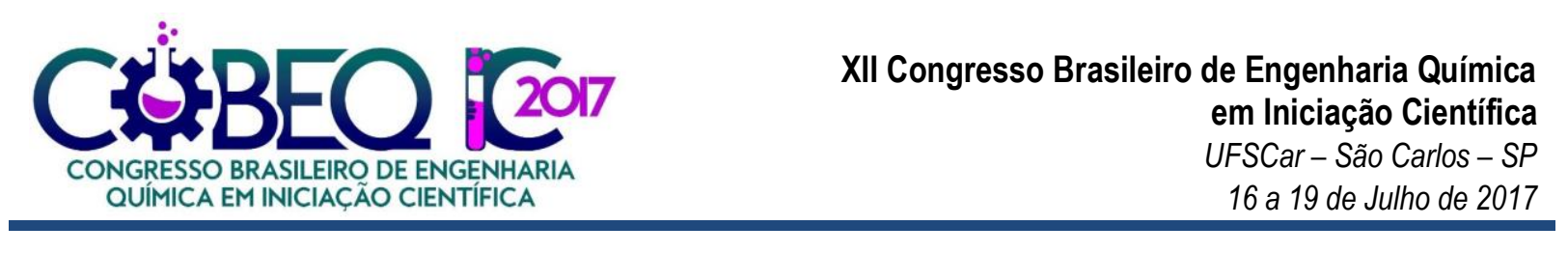

Figura 3 - Extrator Soxhlet B-811

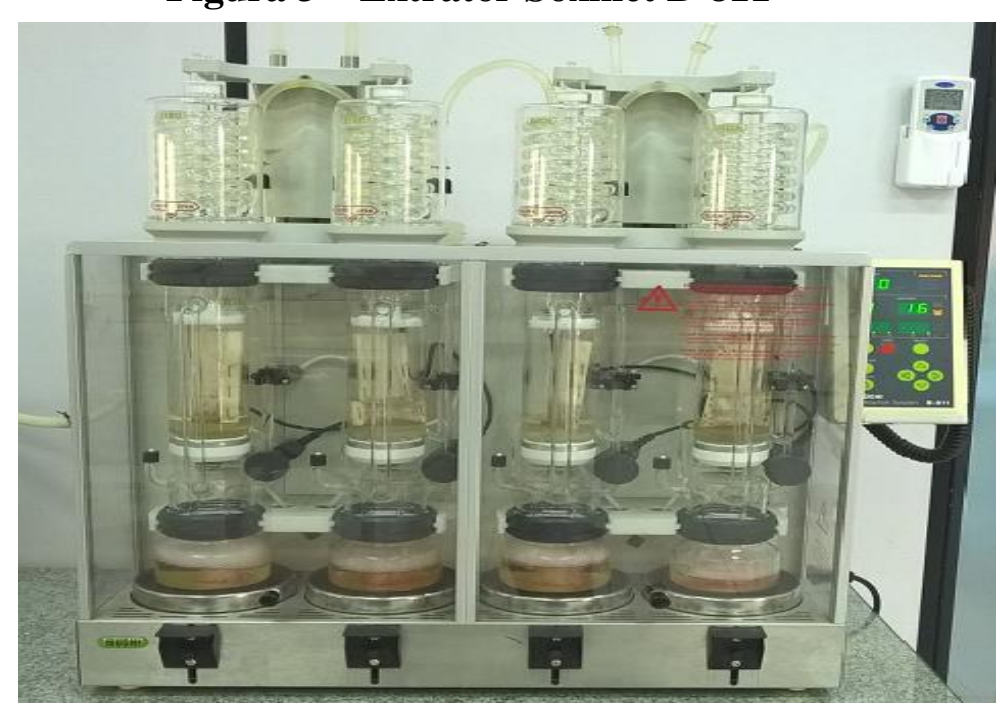

Fonte: Autor (2016)

\section{RESULTADOS E DISCUSSÕES}

Os resultados comparativos da extração do óleo in natura da amêndoa, entre os solventes utilizados, estão detalhados na Tabela 1. Vale ressaltar que a amêndoa foi triturada em liquidificador de uso doméstico.

Tabela 1 - Rendimento da extração por solvente da amostra in natura da amêndoa (TC) com um tempo de 12 horas.

\begin{tabular}{|c|c|c|c|}
\hline \multicolumn{4}{|c|}{ Extração da amostra da amêndoa (TC) in natura por um tempo de 12 horas } \\
\hline Solventes & Etanol & Hexano & Metanol \\
\hline $\begin{array}{c}\text { Medias das Analises em } \\
\text { duplicata }\end{array}$ & $\operatorname{Massa}(g)$ & $\operatorname{Massa}(\mathrm{g})$ & $\operatorname{Massa}(\mathrm{g})$ \\
\hline Sachê de papel filtro & 1,4336 & 1,3264 & 1,3232 \\
\hline Amostra Inicial & 3,2733 & 3,1215 & 3,1110 \\
\hline Sachê + amostra $\left(\mathrm{m}_{\text {inicial }}\right)$ & 4,7069 & 4,4479 & 4,4342 \\
\hline Sache + amostra seca $\left(\mathrm{m}_{\text {final }}\right)$ & 2,9426 & 2,5969 & 2,7969 \\
\hline Amostra seca $\mathrm{m}_{\text {final }}$ & 1,4889 & 1,2704 & 1,4736 \\
\hline $\mathrm{m}_{\text {óleo }} \%$ & $54,485 \pm 0,489$ & $59,321 \pm 1,798$ & $52,601 \pm 2,342$ \\
\hline
\end{tabular}

Fonte: Autor (2016) 
Onde:

$\mathrm{m}_{\text {óleo }}=$ massa de óleo extraída,

$\mathrm{m}_{\text {inicial }}=$ massa da amostra antes do processo de extração,

$\mathrm{m}_{\text {final }}=$ massa da amostra após o processo de extração.

Os resultados mostraram que a eficiência do solvente hexano, sobre a semente in natura, atingiu um percentual de aproximadamente $60 \%$ de óleo extraído. Que possivelmente se deva a maior solubilidade do óleo da TC ao solvente. O etanol apresentou teores próximos, $(54,485 \% \pm 0,489)$ porem o hexano foi mais eficiente. A extração do óleo da amêndoa in natura com o metanol $(52,602 \% \pm 1,798)$ ficou abaixo dos resultados para o etanol e hexano, respectivamente $2 \%$ e $7 \%$, de extração de óleo a menos. Reforçando a hipótese de menor solubilidade como o óleo da amendoeira.

A equiparação da proximidade na eficiência do hexano e o etanol, e importante na escolha entre os dois solventes, tanto no quesito econômico como no ambiental. Pois, de acordo com Santos (2016), o etanol tem um custo menor, é mais facilmente encontrado no mercado, é atóxico e tem operação mais fácil em relação ao hexano. Além disso, o etanol e proveniente de fontes renováveis. Já o hexano é derivado de combustível fosseis.

\section{CONCLUSÕES}

Diante dos resultados obtidos, a Terminalia catappa apresenta um alto teor de óleo, aproximadamente de $60 \%$, o que indica ser uma fonte promissora na produção do biodiesel. $\mathrm{O}$ processo de extação por solvente, para a amêndoa da Terminalia catappa l, foi satisfatório. Porem, vale ressaltar, que é um método que produz residuos quimico, utiliza energia e gera aquecimento do óleo.

Um estudo sobre o controle dos fatores que influenciam o processo de extração, além do solvente, como tempo de residência, granulometria, quantidade de ciclos e tempo de extração, podem maximizar o rendimento do processo.

\section{REFERÊNCIAS}

ANDRADE B. K. S. A. Estudo Do Processo Da Extração Do Óleo Do Pinhão Manso. 2014. Trabalho de Conclusão de Curso (Graduação Em Engenharia Química) - Centro de Tecnologia - Universidade Federal de Alagoas, UFAL. Maceió.

COLLINS, D.J.; PILOTTI, C.A.; WALLIS, F.A.; 1992. Triterpene acids from some Papua New Guinea Terminalia species. Phytochemistry32 (3), 881-884.

DE PAULA, A. A. Caracterização físico-química e avaliação do potencial antioxidante dos frutos da Terminalia catappa Linn. Itapetinga: Universidade Estadual do Sudoeste da Bahia, (Dissertação Mestrado) - Programa de Pós-Graduação em 83 Engenharia de Alimentos, 2008. 91p.

FRANCIS, 1989; LIN, 1992; THOMSON \& EVANS, 2006, apud TEIXEIRA, H.L. Composição Química E Perfil De Ácidos Graxos Da Castanha Do Fruto Da Castanhola (Terminalia Catappa Linn). 2010. 60p. (Dissertação - Mestrado) 
Programa de Pós -Graduação em Engenharia de Alimentos, Área Concentração em Engenharia de Processo. Universidade Estadual Do Sudoeste Da Bahia - UESB, Campus de Itapetinga-BA

KOJIRO, O. I.; Produção E Análise De Bio - Óleo Utilizando Oleaginosas Que Possam Contribuir Para O Aumento Da Matriz Energética Renovável Brasileira. 2010. 65p (Dissertação de Mestrado) - Instituto de química - Universidade Federal de Brasília, Distrito Federal.

REDA, S. Y.; CARNEIRO, P. I. B. Óleos e gorduras: aplicações e implicações. Revista Analytica, n. 27, p. 60-67, Fevereiro/Março de 2007.

SANTOS, J. R. T, Engenheiro Agrônomo Mestre em Produção Vegetal, responsável técnico, Engecampi Projetos e consultorias agroambientais, 2016.

SILVA, I. C. C. Uso de processos combinados para o aumento do rendimento da extração e da qualidade do óleo de macaúba. Dissertação (Mestrado em Tecnologia de Processos Químicos e Bioquímicos), Universidade Federal do Rio de Janeiro, Rio de Janeiro, [s.n.], 2009.

TEIXEIRA, G.A.A. Avaliação do Tempo de Vida Útil de Biodiesel Metílico Obtido a partir da Mistura de Sebo Bovino e Óleos de Soja e Babaçu. Tese de Doutorado. Universidade Federal da Paraíba. Centro de Ciências Exatas e da Natureza. Departamento de Química. Programa de Pós - Graduação em Química. Joao Pessoa, 2010.

THOMSON, L.A.J.; EVANS, B. Terminalia catappa (tropical almond), ver. 2.2. In: ELEVITCH, C.R. (Ed.). Species profiles for pacific Island agroforestry: permanent agriculture resources (PAR), 2006.

VARESCHI, V. 1.979. Plantas entre el mar y latierra. Caracas- Venezuela. Talleres Gráficos Armitano citado por GONZÁLES-MENDOZA et al., 2006. 